\title{
Tercer aniversario del Taller de Papel del IAPH
}

El próximo otoño se cumplirán tres años de la elaboración del primer documento sobre "Objetivos y Funciones" del Taller de Patrimonio Documental y Gráfico del Instituto Andaluz del Patrimonio Histórico. En él se establecía la orientación de las actuaciones a desarrollar por dicho taller durante la primera fase de actividades, marcada especialmente por la instalación, equipamiento y puesta a punto de los métodos de trabajo. Con ello, se completaba la oferta del I.A.P.H. en materia de servicios, investigación y tratamiento del patrimonio histórico andaluz.

Aunque hasta el próximo ejercicio 1999. 2000 no termina totalmente esta fase inicial, a continuación exponemos las actividades que ha desarrollado, y está desarrollando actualmente, dicho taller en esta primera etapa de puesta en marcha.

\section{Instalación y equipamiento básico}

El proyecto de instalación y equipamiento básico se encuentra finalizado actualmente. Con este equipamiento, será posible dar una respuesta satisfactoria a muchos de los principales problemas existentes en los fondos de nuestro patrimonio.

En la distribución espacial del taller, se ha establecido una separación de las distintas áreas de trabajo para mayor comodidad y seguridad en la aplicación de los tratamientos:

a) Zona de tratamientos en seco, que puede funcionar también como zona de recepción y expedición de las obras una vez terminadas las intervenciones.

b) Zona de tratamientos húmedos.

c) Zona de gestión, destinada a la coordinación, elaboración de la documentación y archivo.

En la primera zona, se cuenta con el equipamiento básico para la realización del desmontaje y almacenaje de las obras posterior a su entrada en el taller; durante los tiempos de espera entre los tratamientos; $y$ finalmente, su montaje posterior a la intervención. También en esta zona de trabajo se realiza la aplicación de los tratamientos secos: estudio y análisis de las obras, tratamientos como limpieza mecánica, pruebas de solubilidad de tintas y pigmentos, fijaciones del soporte o la grafía, laminación o forrado, reintegración del soporte, reintegración pictórica, y elaboración de carpetas de conservación.

Su equipamiento consta del mobiliario, maquinaria, instrumental y aparatos específicos mínimos que permitirán la realización de dichos trabajos: mesa de trabajo, archivador planero, soporte porta rollos, mueble y carros auxiliares para albergar instrumental, aparatos y materiales, mesa negatoscopio, lupa binocular, lupa con luz fría de pie, fuente de iluminación con fibra óptica, laminadora con control de temperatura y vacío, selladora de poliéster, cortadora para cartón de passe-partout, etc.

La zona de aplicación de los tratamientos en húmedo -tales como limpieza acuosa, limpieza con disolventes, control de la acidez, estabilización higroscópica, consolidación del soporte, humectación, etc.-, está equipada con el mobiliario, maquinaria, aparatos e instrumental básico para su funcionamiento: fregadero y secadero para papel, mobiliario para aplicación de tratamientos con disolventes, kit de extracción directa para gases tóxicos, lápiz humidificador, y zona de almacenaje de productos y materiales en uso. $\mathrm{Pa}$ ra completar el equipamiento previsto para esta fase se acaba de adquirir la mesa de succión que es fundamental para los tratamientos de obras especialmente delicadas y débiles.

Por último, la zona de gestión, aunque reducida puede cubrir las necesidades básicas inherentes a la coordinación, control de los tratamientos y materiales, elaboración de la documentación e informes, etc.

Actualmente, se ha ampliado el equipamiento con la instalación un taller básico de encuadernación para realizar las intervenciones previstas a un conjunto de obras de carácter documental y bibliográfico seleccionadas por la Consejería de Cultura para ser expuestas en la próxima exposición "Velázquez y Sevilla".

\section{Actividades del taller}

A) Asesoramiento en materia de conservación preventiva, diagnosis y proyectos de intervención o equipamiento

Abarca el asesoramiento en materia de conservación preventiva, diagnosis y proyectos de intervención o equipamiento: estado de conservación, diagnóstico, propuestas de equipamiento, propuestas de conservación, estudio y/o tratamiento de diferentes obras y colecciones.

Desde que inició sus actividades, a finales de 1996, se han podido atender demandas en esta materia de instituciones tales como el A.H.M. de Carmona, A.H.M. de Sevilla, colección Vázquez Díaz del Ayuntamiento de Nerva (Huelva), colección de Patrimonio Nacional en los RR. Alcázares de Sevilla, A.H.P. de Cádiz, M.A.C. de Puebla de Cazalla, A.H. del Seminario de Sevilla, A.H.M de La Palma del Condado, Cabildo de la Catedral de Sevilla, Delegación Provincial de la Consejería de Turismo y Deporte de Sevilla, patrimonio documental y bibliográfico seleccionado por la Consejería de Cultura para la exposición "Velázquez y Sevilla", Ayuntamiento de SeviIla, Real Sociedad Económica Sevillana de Amigos del País, A.H.M de Palos de la Frontera (Huelva), A.H.M. de Almería, etc.

\section{B) Intervención en bienes del patrimonio documental andaluz}

Dentro de esta línea de actuación se ha venido elaborando la documentación específica para el funcionamiento y control de las actividades del taller y su normalización para la aplicación de los tratamientos de conservación para el documento gráfico. También, con carácter de puesta a punto del método, se ha trabajado sobre los documentos de interés histórico-artístico adjuntos a obras tratadas en el I.A.P.H.

Además, hasta la fecha, se han realizado los siguientes tratamientos:

- Aplicación de tratamientos de desinsectación/desinfección (Doc. Ms. -sello de ceradel A.H.M. de Carmona, Doc. Ms. -perga- 
Noticias y

mino- del A.H.M. de La Palma del Condado, fondos documentales del A.H. del Seminario de Sevilla, dibujos de Murillo -papel- del Ayunt. de Sevilla, Docs. Ms. del Ayunt. de Arjona y Docs. Ms. Arjonilla).

- Intervenciones de urgencia (6 proyectos de arquitectura para la Fundación Mies van der Rhoe de Barcelona).

- Aplicación de tratamientos de conservación a la documentación adjunta a otras obras del patrimonio histórico (docs. de autoría, doc. administrativa o histórica valiosa, etc.).

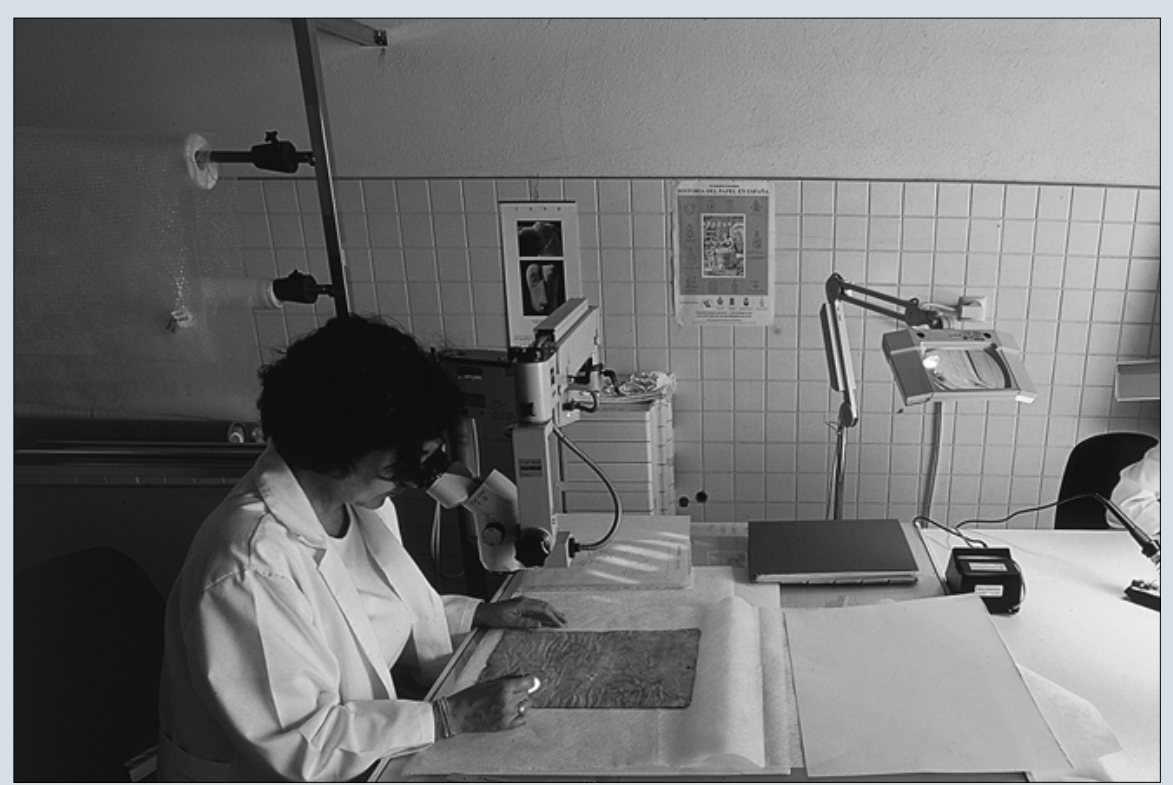

En estos momentos, dentro de la programación para el ejercicio 1998-1999, se están realizando intervenciones en varias obras: Doc. (ms.) y sello de cera del A.H.M. de Carmona (Sevilla), Doc. (ms.) del A.H.M. de La Palma del Condado (Huelva), Dibujo del Ayuntamiento de Sevilla, Docs. (ms.) del A.H.M de Arjona (Jaén) y Docs. (ms.) del A.H.M. de Arjonilla (Jaén).

\section{C) Investigación aplicada a la conservación del patrimonio documental}

En este campo, el taller ha finalizado un trabajo de investigación aplicada a la conservación del patrimonio documental, realizada, en este caso, a la Carta de Privilegio del A.H.M. de La Palma del Condado, en la que Enrique III concede la celebración de la feria anual a dicha localidad. Su título es "Tratamiento de la grafía documental en soporte digital: Recuperación de la legibilidad de textos con alteraciones" y con él se han logrado dos objetivos fundamentales: Investigar sobre el tratamiento digital de imágenes para su aplicación, como método no destructivo, en el estudio documental de textos con alteraciones, e introducir a los becarios adscritos al primer programa de formación del Centro de Intervención (áreas de papel, fotografía y química), en la dinámica del trabajo de equipo interdisciplinar del I.A.P.H.

Siguiendo la línea de los contactos iniciados, dentro del programa de actuaciones, con archivos, bibliotecas y museos de nuestra comunidad, se ha elaborado un proyecto para gación: "Estudio analítico del material de conservación utilizado en Archivos, Bibliotecas y Museos: Idoneidad y composición". En este caso, teniendo en cuenta las necesidades de los centros, las sugerencias recibidas y las solicitudes de asesoramiento en esta materia, se trataría de comprobar la adecuación del material de conservación utilizado para almacenaje y archivo de fondos documentales y gráficos en Andalucía, a fin de establecer una tipología homologada que responda a las necesidades de los centros y que cumpla efectivamente con su función de preservación del patrimonio.

\section{D) Formación}

El Taller ha participado en la elaboración y puesta en práctica del primer programa de formación, iniciado en el Centro de Intervención durante el curso 1996-97, y 97-98, para personal especializado en materia de conservación-restauración de patrimonio documental y gráfico, y este año volverá a participar en el segundo programa que comienza en octubre próximo.

También ha participado en la elaboración del programa de formación de personal especializado, dentro del marco de colaboración con Marruecos, y, durante los ejercicios 97-98 y 98-99, ha organizado, dirigido y coordinado dos cursos monográficos para especialistas:

- "Intervención en Patrimonio Documental de Archivo: Restauración de Sellos Medievales", realizado en el A.H.P. de Cádiz, en marzo de 1998.

- "Técnicas de identificación y análisis aplicadas a la conservación del Patrimonio Documental y Gráfico", realizado en el I.A.P.H., en noviembre de 1998.

\section{F) Otras actividades}

El personal del taller ha realizado también otras actividades caracterizadas dentro del marco de las relaciones, colaboraciones y convenios con otros centros e instituciones similares -Instituto del Patrimonio Histórico Español, Biblioteca Nacional, Centro de Arte Reina Sofía, en Madrid; Archivo de la Corona de Aragón, Archivo Nacional de Catalunya, en Cataluña; Archivo General de Indias de Sevilla, etc.-, tendentes a potenciar el intercambio de experiencias e ideas, así como la colaboración mutua en materia de conservación-restauración del patrimonio. La más reciente, su participación en el "I Congreso Nacional sobre Bibliofilia, Encuadernación Artística, Restauración y Patrimonio Bibliográfico" (Mesa Redonda y Talleres, sección de Restauración), celebrado en Cádiz del 21 al 24 de abril de 1999.

Eulalia Bellón Cazabán, Coordinadora del Taller de Patrimonio Documental y Gráfico, IAPH 